\title{
Effects of Pomace Fertilization on some Phenological, Morphological and Biochemical characters of the Cherry tree in the Region of Tlemcen (Algeria): Case of the Black Bigareau and Sunburst
}

\author{
Soulef Hamed ${ }^{1}$, Linda Abi-Ayad ${ }^{1}$, Baha-Eddine Ghezlaoui-Bendi-Djelloul ${ }^{1,2^{*}}$ \\ Mohammed Souddi, ${ }^{1,3}$ \\ ${ }^{1 *}$ Laboratory of Ecology and Management of Natural Ecosystems, Faculty of Natural and Life Sciences, \\ and Earth and Universe Science, University of Tlemcen, B.P 13000. Algeria. \\ $2^{*}$ Department of Agronomy, Faculty of Natural and Life Sciences, and Earth and Universe Science, \\ University of Tlemcen, B.P 13000 Algeria. \\ ${ }^{3}$ Department S.N.V., Faculty of Science and Technology, Ahmed Draria University, Adrar, Algeria.
}

Received December, 2020; Revised March, 2021; Accepted April, 2021

\begin{abstract}
Pomace is the solid residue by-product resulting from the extraction of olive oil. Their high content of organic compounds gives them the possibility of being used also as green manure. We have tried this amendment approach on two varieties of cherry grown in the Tlemcen region. The Sunburst and the Black Bigarreau. Its use in combination with N.P.K fertilizers increases the carbon content of the soil, boosts the formation of May bouquets, and improves the water-holding capacity of the clay-humic complex. The results of this study showed that olive pomace used as a fertilizer, alone or in combination with N.P.K mineral fertilizers creates an advantage on the phenological and biochemical aspect, especially on the Black Bigarreau variety.
\end{abstract}

Keywords: Algeria, compost, pomace, Cherry, fertilizer.

\section{Introduction}

World production of pomace is estimated at 2.9 million tonnes. In Algeria, it is 156.104 quintals/year [1]. So in order to reduce the amount of his wasts, a considerable number of valorisation methods of olive pomace have been studied in the last years. Olive pomace has been explored as a biomass source for biorefineries to produce second-generation ethanol [2], for agricultural use as compost or as irrigation water [3] and as a component in the manufacture of different materials as lightweight aggregates [4]. Additionally, more studies about the recovery of value-added products have been explored using conventional solvent-extraction or non-

\footnotetext{
* Corresponding author: Baha-Eddine Ghezlaoui-BendiDjelloul, Email: ghezlaoubahae@gmail.com (cc)) EY-NC-ND $\odot 2021$ S. Hamed et al., published by De Gruyter Open. This work was licensed under the Creative Commons Attribution-NonCommercialNoDerivs 3.0 License
}

conventional extraction techniques (e.g., microwave-assisted, enzyme-assisted and supercritical fluid extraction) [5]. Nevertheless, in these previous studies, only low amounts of olive pomace were used, or merely a small fraction was valorised (often phenolic compounds), leaving the majority of olive pomace untreated [6]. Besides that, some of these approaches are not sustainable (the use of water or solvents) or possess high total operational costs [5]. Therefore, under the aim of a transition from a non-sustainable linear economy (take-makedispose of) to a circular bioeconomy wich maintain the value of products and materials for as long as possible. While minimising resource use and waste generation of the olive oil sector, higher-value uses should be prioritised over the current energy and compost valorisation [7]. This work spreads out the different aspects of soil fertilization with pomace. This technique is not 
really new; it has existed since the $2^{\text {nd }}$ century B.C. This technique of fertilization has come to shake up the received ideas which made pass the waste of the olive trees as harmful for the plants and the environment [8] while generating significant economic added value. However, the use of these elements obeys parameters that must be respected [9]. For vegetable water (margin), it must be stored three months before use. Then, between 5 and 10 liters on the square meter of soil and plow [10]. The pomace must also remain three months before its use. It is then spread on the ground and mixed with straw to pouring as fertilizer [11]. This work aims to popularize and inform about this technique of soil fertilization which, it seems, gives excellent results [9]. The region of Tlemcen is an area in which arboriculture occupies a fundamental place, especially olive growing and, to a lesser extent, the cultivation of cherry trees. In this work it would be very interesting to evaluate the fertilizing contribution of the olive pomace of the region on the phenological, morphological and bio-chemical (fruit) aspect of the cherry tree of the region. Our approach has been oriented towards the most cultivated varieties, in particular Sunburst and Black Bigarreau.

\section{Material and Methods}

Experience site

The "Chikhi" farm where the experiment was carried out is part of the commune of Ain Fezza, wilaya of Tlemcen with the coordinates $34.87^{\circ}$ latitude and $-1.23^{\circ}$ longitude (Figure 1 ). The area of this farm is 8 hectares including 7 hectares of cherry trees (3025 trees) and 1 hectare occupied by other crops (Satellite photo Figure. 1).
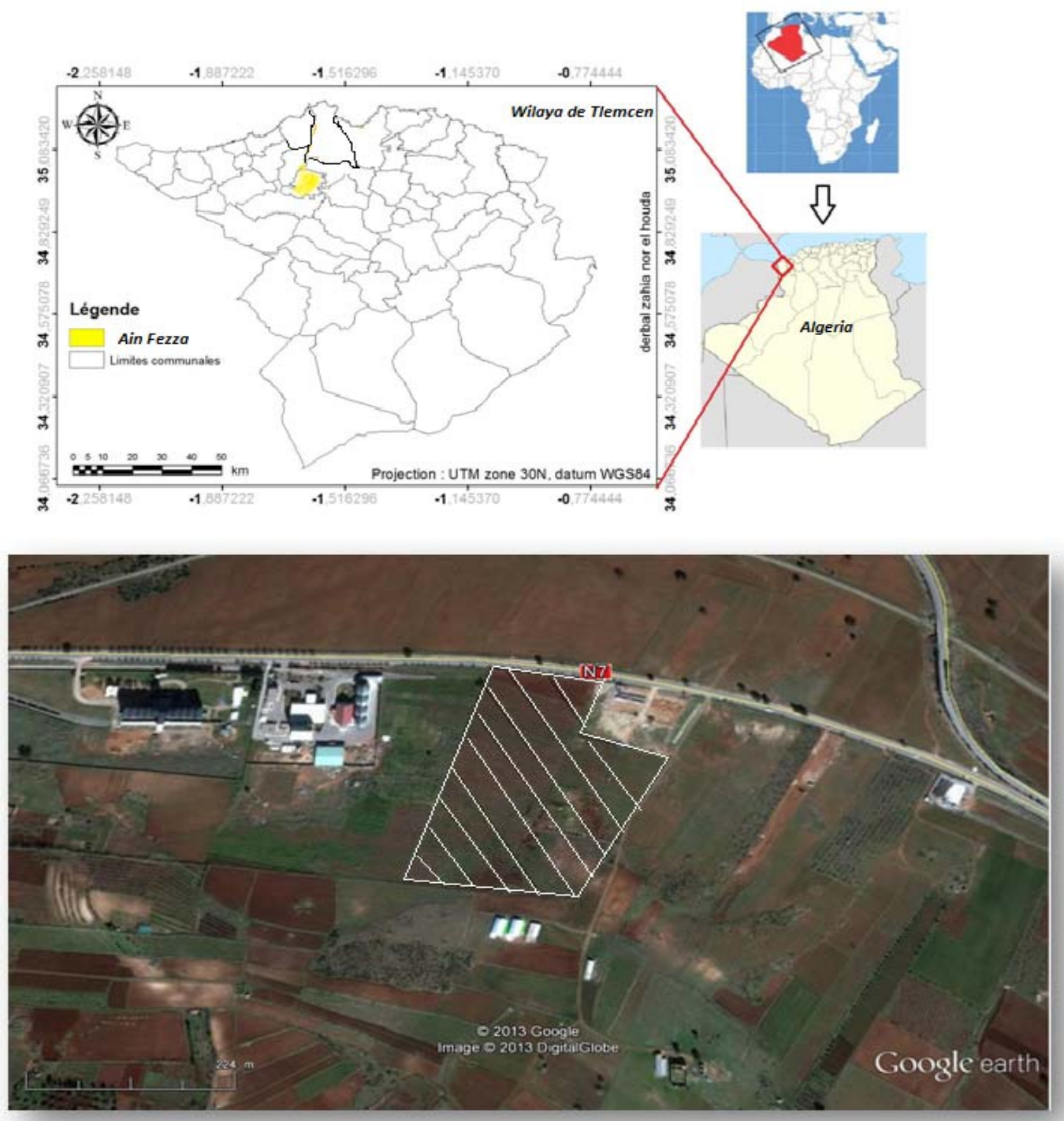

Figure 1. Geographical location and Satellite view of Mr Chikhi's farm [13]. 
The orchard is on a mid-slope, a frost-free situation. The climate is characterized by a period of drought that lasts for 4 to 6 month per year. Our region corresponded to the semi-arid bioclimatic stage with a temperate winter. The physical and chemical analysis of soil samples taken from the orchard was carried out at the soil laboratory of Abou Bekr Belkaid Tlemcen University. The results of the particle size analysis were done by the Casagrande method and showed that the soil texture was silty-clay. The results of the determination of the total limestone by the Bernard calcimeter method [12] showed that the soil of the exploitation was a non- calcareous soil. In regard to the $\mathrm{pH}$, the soil approaches neutrality [13].

Test culture

For this study we did choose two varieties of cherry based on their availability at the experimental station. The Black Bigarreau, (Figure 2) cultivated in 2007, considered as one of the ancient varieties in Tlemcen, very commercialized and appreciated by the local population; characterized by a dark red color almost black, a sweet taste and a great caliber. The Sunburst, (Figure 2) cultivated in 2009; introduced to the region by the owner himself, very productive, the fruits are red, large in size with a moderately sweet and low acid.

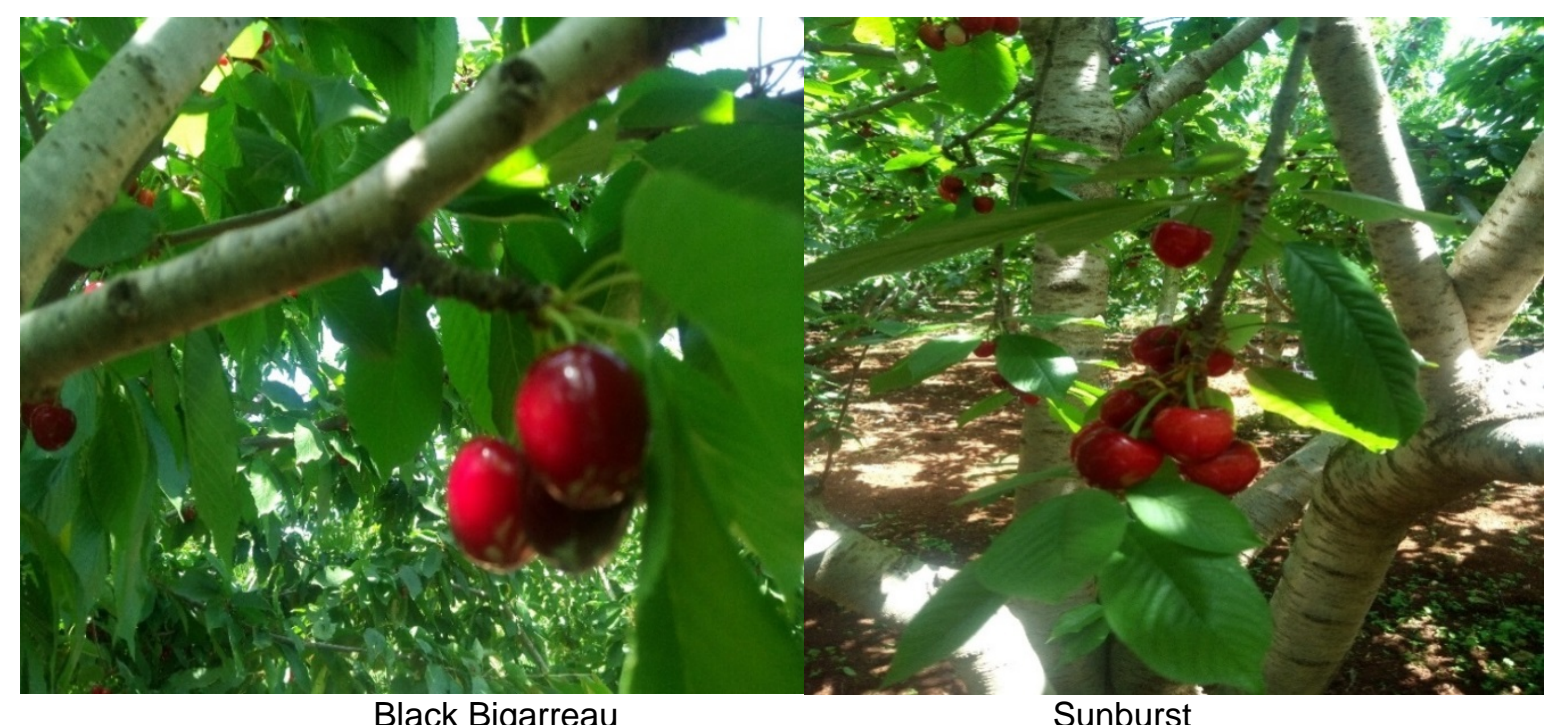

Figure 2. Fruit of Black Bigarreau and Sunburst [13]

\section{Type of fertilizers}

Mineral fertilizer: The owner brings little maintenance fertilizer, the P.K (20/25) amended in December with a total quantity of $18 \mathrm{~kg}$, as well as nitrogen due to $300 \mathrm{~g} /$ tree where a quantity was used, total of $36 \mathrm{~kg}$. The first dose is applied before bud break in February and the second after harvest in July. The mineral fertilizers were produced by SORFERT Algeria (E.P.E ASFERTRADE S.P.A, subsidiary of industrial group A.S.M.I.D.A.L.) [14].

Pomace: The pomace was collected from traditional olive mills in the region. The sample was dried on the experimental site in the open air for a period of more than 3 years. The bio-fertilizer was already used by the farmer for economic reasons (the high prices of mineral and organic fertilizers in the local market), as well as for soil softening. The total amount applied to both varieties of cherry is $360 \mathrm{~kg}$. This semi-solid effluent has a water content of approximately $65 \%$, a slightly acidic $\mathrm{pH}$, a very high organic matter content and a considerable proportion of fat (Table 1) [15] 
Physico-chemical composition of olive pomace (value in dry weight)

\begin{tabular}{|c|c|}
\hline Parameters & Values \\
\hline$\overline{\mathrm{pH}}$ & 5.15 \\
\hline Humidity (g.100g-1) & 55.80 \\
\hline Co (g.100g-1) & 51.77 \\
\hline $\mathrm{C}_{6} \mathrm{H}_{6} \mathrm{O}(\mathrm{mg} \cdot \mathrm{g}-1)$ & 12.37 \\
\hline Fat (g.100g-1) & 10.93 \\
\hline N Total (mg.g-1) & 1.18 \\
\hline P. Total (mg.g-1) & 0.15 \\
\hline K. Total (mg.g-1) & 1.03 \\
\hline Zn. (mg.g-1) & 20.00 \\
\hline Mn.(mg.g-1) & 10.00 \\
\hline
\end{tabular}

Table 1.

Experimental setup: in this study 6 treatments were tested in addition to 2 controls without fertilizer. The experimental setup consists of 2 complete random blocks. Each block had 4 plots of $6 \mathrm{~m}$ wide and $62 \mathrm{~m}$ long. In each plot, a single

T1: Organic fertilizer $\longrightarrow$ Pomace

T2: Mineral fertilizer $\longrightarrow$ N.P.K

T3: Combined fertilization

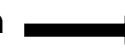
Pomace + N.P.K

T0*: Witness

$\longrightarrow$ No fertilizer

T1*: Organic fertilizer Pomace

T2*: Mineral fertilizer

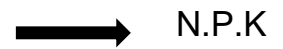

T3*: Combined fertilization
Block 1: Sunburst

treatment was applied to 15 trees, nearly uniform in growth, vigor and productivity within the same variety. The different fertilization treatments are as follows:

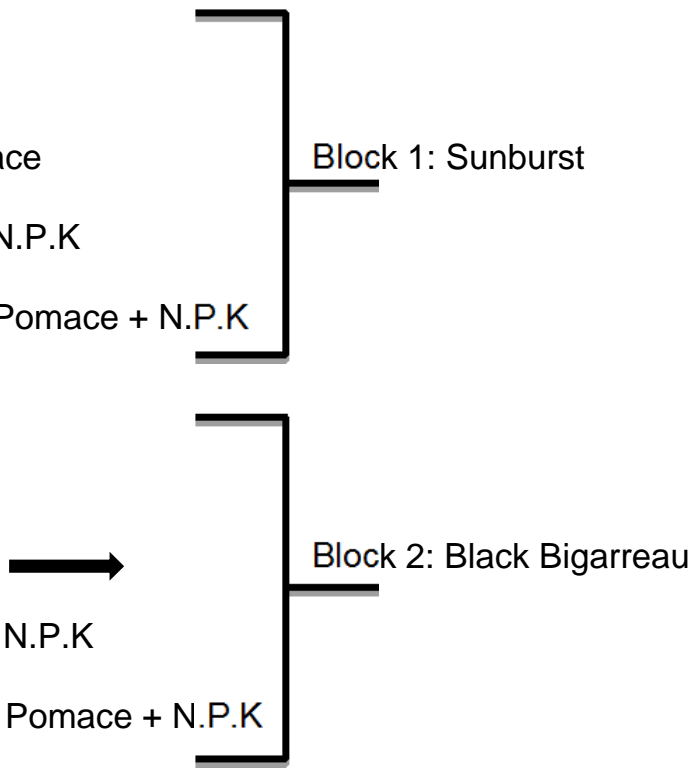

Conduct of the experiment:

The fertilizers were applied 3 times during the experiment (2017-2019). The nitrogen and olive pomace were both used before bud break in February (02/29/2018) and after harvest in July (from 07/31/2018) while the P.K fertilizers were applied in December (12/15/2017). For this investigation we prepared the soil with a superficial plowing between rows and around trees (burial of weeds). The olive pomace was weighed then amended around the trees (T1, T3, $\left.\mathrm{T}^{*}, \mathrm{~T}^{*}\right)$. The same process is done for the mineral fertilizers (T2, T3, T2*, T3*). The remaining plots $\left(\mathrm{TO}, \mathrm{TO}^{\star}\right)$ were used there as controls (without any treatment). In each plot 15 trees were planted $4 \times 4 \mathrm{~m}$ under drip irrigation system, where block 1 contains the Sunburst variety and block 2 contains the Black Bigarreau variety.

Determining the flowering rate:

After the application of the treatments we counted the bouquets of May (from 12/03/2019 to 17/03/2019) for the two varieties, 3 branches were chosen and marked in a random way from each 
tree. Then we carried out a count of flowers per May bouquet (from 04/05/2019 to 04/10/2019) in order to assess the effect of fertilizers on the flowering rate and therefore the production (Table 2).

Different phenological stages of Bigarreau noir and Sunburst

\begin{tabular}{ccccc} 
& \multicolumn{2}{c}{ Black Bigarreau } & \multicolumn{2}{c}{ Sunburst } \\
\cline { 2 - 5 } & $\mathbf{2 0 1 8}$ & $\mathbf{2 0 1 9}$ & $\mathbf{2 0 1 8}$ & $\mathbf{2 0 1 9}$ \\
\hline Phenological stage & & & & \\
& $18 / 02 / 2018$ & $19 / 02 / 2019$ & $19 / 02 / 2018$ & $21 / 02 / 2019$ \\
Bud dormancy & $04 / 03 / 2018$ & $13 / 03 / 2019$ & $07 / 03 / 2018$ & $17 / 03 / 2019$ \\
Bud break & $04 / 03 / 2018$ & $14 / 03 / 2019$ & $08 / 03 / 2018$ & $17 / 03 / 2019$ \\
blooming & $25 / 04 / 2018$ & $12 / 04 / 2019$ & $23 / 04 / 2018$ & $12 / 04 / 2019$ \\
Fruit set & $12 / 05 / 2018$ & $19 / 05 / 2019$ & $14 / 05 / 2018$ & $19 / 05 / 2019$ \\
fruiting & & & & \\
\hline
\end{tabular}

Morphological study of fruits seeds and leaves. On 06/12/2019 we collected 100 fruits per plot at random. The samples were transported immediately to the laboratory to avoid any form of fermentation of the pulp [16]. The harvested fruits were measured and weighed where we used a graduated ruler and a precision balance to proceed with the measures of The length of the peduncle, the length, the width and the weight of fruits. Pulping is done manually after a pressing operation. The seeds are rubbed together to remove the pulp particles that adhere to the pits. After cleaning, the wet seeds are spread in a thin layer and turned over from time to time to homogenize the drying. Empty, malformed or parasitized seeds are eliminated. The samples are weighed before, then after drying in an oven at $105^{\circ} \mathrm{C}$ for 24 hours [17].

-Water content $(\%)=($ Fresh weight - Dry weight)/Fresh weight $\times 100$

After the fruits we collected 100 leaves from each plot $(07 / 13 / 2019)$ where the measurements of length and width were taken by using an AM.350 leaf planimeter. Then we weighed each of them before, then after drying in an oven at $138^{\circ} \mathrm{C}$ for 24 hours [17]. The measurement work was done at the laboratory of Abu Bekr Belkaid University.
Sugar level evaluation

After pressing the fruits in a small mortar, the sugar level was evaluated by using an ABBEMAT 300 Refractometer from the ABBEMAT ANTON PAAR brand, set at a temperature of $25^{\circ}$ or the index of the distilled water is of $\mathrm{nD} 25=1.332520$.

\section{Soil sampling}

On 07/20/2019, 8 soil samples were taken (15 sub-samples per treatment). The quantities of soil were taken from the root zone at a depth of 0-20 $\mathrm{cm}$. For a better homogenization we mixed well each sample, then we took them to the laboratory where granulometic analyzes were carried out by the Casagrande method (rate of clay, silt, sand and gravel) [18]. The water content of each sample was measured by the weighing operations before and after drying in the oven at $105^{\circ} \mathrm{C}$ for $24 \mathrm{~h}$ [12]. To determine the level of organic matter, $50 \mathrm{~g}$ of each sample were weighed before and after drying in an oven at a temperature of $450^{\circ} \mathrm{C}$ for $3 \mathrm{~h}$. (Table 4 )

\section{Results and Discussion}

Evaluation of sugars

The refractometer showed different results between the two varieties. For sunburst, the sugar level is higher in T0 (1.357195), while it is found higher in $\mathrm{T}^{*}$ (1.362852) for Black Bigarreau (Table 3).

Table 3.

The result of the May flowers bouquets count and sugar evaluation

\begin{tabular}{l|cccc|cccc}
\hline & \multicolumn{4}{|c|}{ Sunburst } & \multicolumn{4}{c}{ Black Bigarreau } \\
\hline Results & T0 & T1 & T2 & T3 & $T^{*}$ & T1 $^{*}$ & T2 $^{*}$ & T3 $^{*}$ \\
NB of MB/B & $38.06 \pm 0.00$ & $41.93 \pm 0.00$ & $39.2 \pm 0.00$ & $35 \pm 0.00$ & $29.26 \pm 0.0066$ & $16.6 \pm 0.00$ & $38.26 \pm 0.0066$ & $36.33 \pm 0.0033$ \\
NB of F/ MB & $163.4 \pm 0.00$ & $201.4 \pm 0.00$ & $196.33 \pm 0.00$ & $163.53 \pm 0.00$ & $119.26 \pm 0.00$ & $117.8 \pm 0.00$ & $163.33 \pm 0.0033$ & $170.33 \pm 0.0033$ \\
FS level \% & $1.35 \pm 0.0071$ & $1.35 \pm 0.0054$ & $1.35 \pm 0.0058$ & $1.35 \pm 0.0053$ & $1.35 \pm 0.0095$ & $1.36 \pm 0.0028$ & $1.36 \pm 0.0009$ & $1.36 \pm 0.0003$ \\
\hline
\end{tabular}

NB of MB/B: Number of may bouquet/branche. NB of F/MB: Number of flowers/may bouquet. FS level\%. 
Flower yield per treatment

The flower count results are shown in (Table 3), where the May bouquet averages per branch for the Sunburst variety are as follows; 38.06 (T0), 41.93 (T1), 39.2 (T2) and 35 (T3), whereas the average of flowers per May bouquet are: 163.4 for the control plot, 201.4 for the plot amended by Pomace, 196.33 for N.P.K. and for the combined fertilizers we had 163.53. The Black Bigarreau presented the following averages; 29.26, 16.6, $38.26,36.33$ and $119.26,117.8,163.33,170.33$ for $\mathrm{T}^{*}, \mathrm{~T}^{*}, \mathrm{~T}^{*}, \mathrm{~T}^{*}$. We noted that the high number of May bouquet per branch was observed on the Sunburst. The olive pomace has increased significantly the number of flowers by May bouquet [19]. On the other hand in the Black Bigarreau it was the combined fertilizer which had more influence on the flower load [20].

\section{Soil analysis}

The soil properties after the applied analyzes, presented in Table. 4, allowed us to know the type of soil of each block. For both varieties we had a sandy loam soil, as well as a higher percentage of organic matter and water content in the plots treated with pomace fertilizer[21].

The results of soil analyzes

\begin{tabular}{|c|c|c|c|c|c|c|c|c|}
\hline & \multicolumn{4}{|c|}{ Sunburst } & \multicolumn{4}{|c|}{ Black Bigarreau } \\
\hline Results / \% & T0 & $\overline{T 1}$ & $\mathrm{~T} 2$ & T3 & TO & $T 1^{*}$ & $\mathrm{~T}^{\mathrm{x}}$ & $T 3^{x}$ \\
\hline Clay & 19 & 19 & 14 & 17 & 18 & 25 & 13 & 16 \\
\hline Silt & 20 & 30 & 23 & 19 & 22 & 32 & 26 & 23 \\
\hline Sand & 56 & 42 & 60 & 48 & 58 & 41 & 58 & 58 \\
\hline Gravel & 6 & 8 & 4 & 16 & 2 & 2 & 3 & 3 \\
\hline Tamissat/0.08mm & 75 & 76 & 66 & 62 & 71 & 92 & 75 & 78 \\
\hline Tamissat/2mm & 94 & 92 & 96 & 84 & 98 & 98 & 97 & 97 \\
\hline $\begin{array}{l}\text { Organic matter } \\
\text { Water content }\end{array}$ & $\begin{array}{c}8.4 \\
12.79\end{array}$ & $\begin{array}{c}13.7 \\
17.73\end{array}$ & $\begin{array}{c}8 \\
14.25\end{array}$ & $\begin{array}{c}10.5 \\
16.85\end{array}$ & $\begin{array}{c}7.4 \\
12.14\end{array}$ & $\begin{array}{c}9 \\
13.83\end{array}$ & $\begin{array}{c}7.3 \\
12.12\end{array}$ & $\begin{array}{c}8 \\
13.9\end{array}$ \\
\hline
\end{tabular}

\section{Multivariate analysis}

The multivariate analysis (principal component analysis) obtained by the Minitab 17 software allowed us to obtain graphs which generate a set of linear combinations, sufficient to analyze the relationships and interactions between the various variables selected namely: The morphometric parameters, the type of fertilizer, the water content of the seed and the percentage of sugar in the fruit. The results of the four-combination matrix for the two varieties are shown in Table 5, Figure 3 and 4 .

Table 5.

Results of morphometric measurements of fruits, leaves and grains of Sunburst and Black Bigarreau

\begin{tabular}{|c|c|c|c|c|c|c|c|c|}
\hline & \multicolumn{4}{|c|}{ Sunburst } & \multicolumn{4}{|c|}{ Black Bigarreau } \\
\hline Results & TO & $\mathrm{T} 1$ & $\mathrm{~T} 2$ & T3 & $\mathrm{TO}^{*}$ & $\overline{T 1^{*}}$ & $\mathrm{~T}^{*}$ & $\mathrm{T3}^{\star}$ \\
\hline $\mathrm{FW} / \mathrm{g}$ & $8.86 \pm 0.0065$ & $8.66 \pm 0.0001$ & $9.89 \pm 0.0047$ & $9.75 \pm 0.0034$ & $7.34 \pm 0.0019$ & $7.67 \pm 0.0094$ & $7.47 \pm 0.0011$ & $7.49 \pm 0.0083$ \\
\hline $\mathrm{FL} / \mathrm{cm}$ & $2.60 \pm 0.0085$ & $2.34 \pm 0.0070$ & $2.72+0.0003$ & $2.58 \pm 0.0057$ & $2.44 \pm 0.0092$ & $2.45 \pm 0.0019$ & $2.51+0.0056$ & $2.44 \pm 0.0018$ \\
\hline $\mathrm{PL} / \mathrm{cm}$ & $3.83 \pm 0.0058$ & $3.66 \pm 0.0015$ & $4.16 \pm 0.0003$ & $3.88 \pm 0.0025$ & $3.30 \pm 0.0041$ & $3.23 \pm 0.0077$ & $3.40 \pm 0.0083$ & $3.28 \pm 0.0091$ \\
\hline $\mathrm{FSW} / \mathrm{g}$ & $0.36 \pm 0.00$ & $0.37 \pm 0.00$ & $0.33 \pm 0.002$ & $0.34 \pm 0.0070$ & $0.35 \pm 0.0034$ & $0.36 \pm 0.0052$ & $0.36 \pm 0.0011$ & $0.38 \pm 0.0070$ \\
\hline $\mathrm{DSW} / \mathrm{g}$ & $0.22+0.00$ & $0.22+0.002$ & $0.21+0.0038$ & $0.20 \pm 0.0052$ & $0.23 \pm 0.00$ & $0.23 \pm 0.0052$ & $0.23 \pm 0.0022$ & $0.25 \pm 0.0011$ \\
\hline $\mathrm{SH} / \%$ & $38.88 \pm 0.00$ & $40.54 \pm 0.00$ & $36.36 \pm 0.00$ & $41.17 \pm 0.00$ & $34.28 \pm 0.00$ & $36.11+0.00$ & $36.11+0.00$ & $34.21+0.00$ \\
\hline $\mathrm{LW} / \mathrm{cm}$ & $5.76 \pm 0.008$ & $6.18 \pm 0.008$ & $6.30 \pm 0.004$ & $6.03 \pm 0.002$ & $6.08 \pm 0.004$ & $5.84 \pm 0.008$ & $5.84 \pm 0.004$ & $6.16 \pm 0.004$ \\
\hline $\mathrm{LL} / \mathrm{cm}$ & $12.87 \pm 0.002$ & $13.20 \pm 0.004$ & $14.74 \pm 0.008$ & $12.94 \pm 0.008$ & $12.17 \pm 0.002$ & $12.39 \pm 0.002$ & $12.96 \pm 0.004$ & $12.91+0.006$ \\
\hline $\mathrm{LS} / \mathrm{cm}$ & $74.24 \pm 0.0056$ & $81.70 \pm 0.0063$ & $92.97 \pm 0.0013$ & $78.10 \pm 0.0023$ & $74.05 \pm 0.0044$ & $72.46 \pm 0.0084$ & $75.76 \pm 0.0016$ & $79.61+0.0042$ \\
\hline FLW/g & $0.75 \pm 0.0088$ & $0.85 \pm 0.0044$ & $1.02+0.0032$ & $0.72+0.0076$ & $0.85 \pm 0.0068$ & $0.77 \pm 0.006$ & $0.81+0.006$ & $0.92+0.0068$ \\
\hline DLW/g & $2.72+0.00$ & $0.29 \pm 0.0008$ & $0.36 \pm 0.0068$ & $0.25 \pm 0.0072$ & $0.30 \pm 0.0068$ & $0.31+0.00$ & $0.30 \pm 0.0088$ & $0.35 \pm 0.0048$ \\
\hline LH/\% & $64 \pm 0.00$ & $65.88 \pm 0.00$ & $64.7 \pm 0.00$ & $65.27 \pm 0.00$ & $64.7 \pm 0.00$ & $59.74 \pm 0.00$ & $62.96 \pm 0.00$ & $61.95 \pm 0.00$ \\
\hline
\end{tabular}

FW/g: Fruit weight/g. FL/cm: Fruit length/cm. PL/cm: Peduncle length /cm. FSW/g: Fresh Seed weight/g. DSW/g: Dry Seed weight/g. SH/\%: Seed humidity/\%. LW/cm: Leaf width/cm. LL/cm: Leaf length/cm. LS/cm: Leaf surface $/ \mathrm{cm}$. FLW/g: Fresh leaf weight/g. DLW/g: Dry leaf weight/g. LH/\%: Leaf humidity/\% 


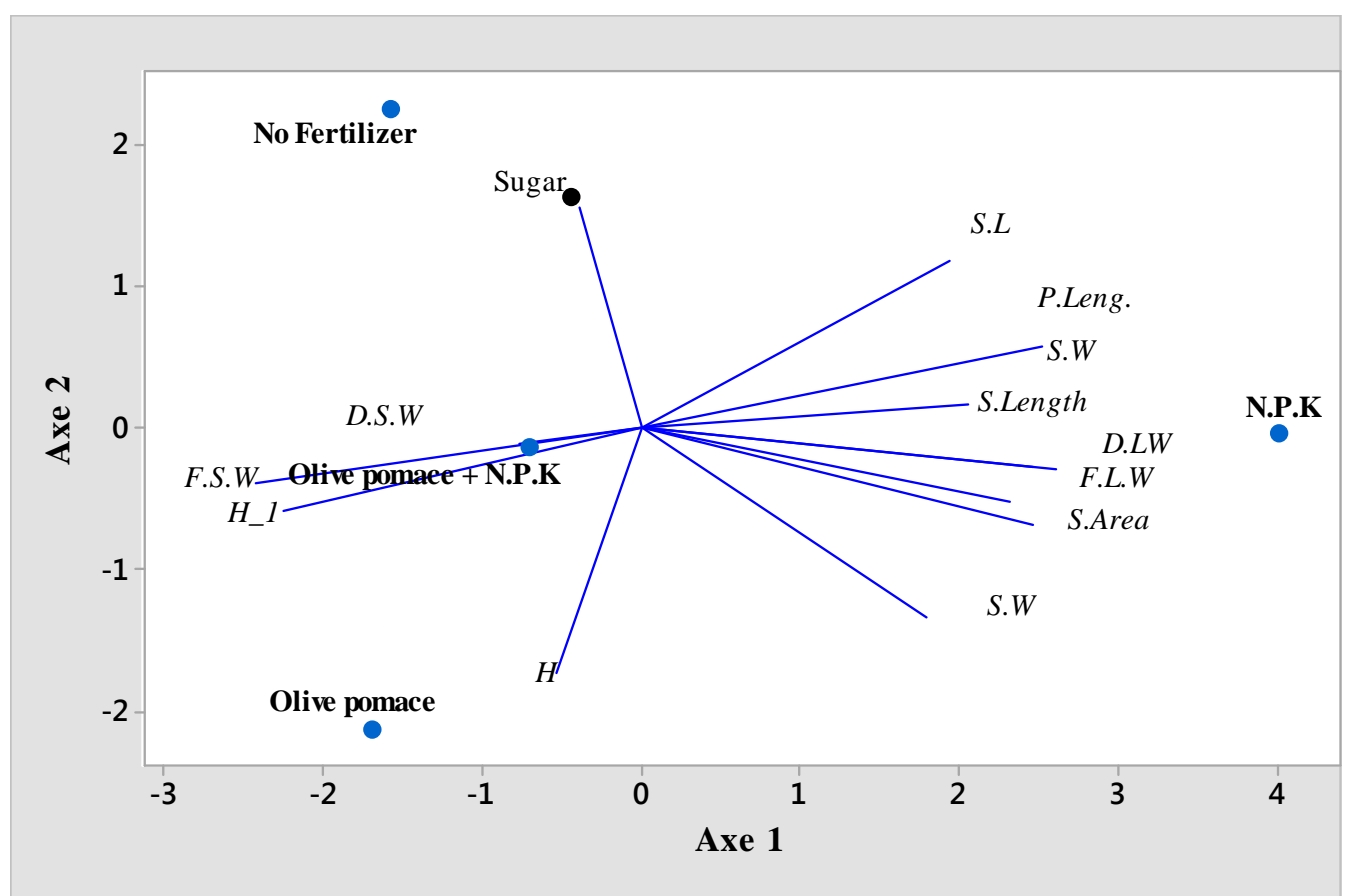

D.SW: Dry seed weight, F.SW: Fresh seed weight, H1: Seed humidity, H: Leaf humidity, S.Area: Sheet area or leaf surface, F.LW: Fresh leaf weight,

D.LW: Dry leaf weight, S.length: Sheet length, S.W: Sheet width,

P.Leng: Peduncle length. S.L: Sunburst fruit length, S.W: Sunburst fruit weigth.

Figure 3. Projection on the factorial plane of the A.C.P. factors of morphometric variations, types of fertilizers and \% of sugar. (Sunburst)

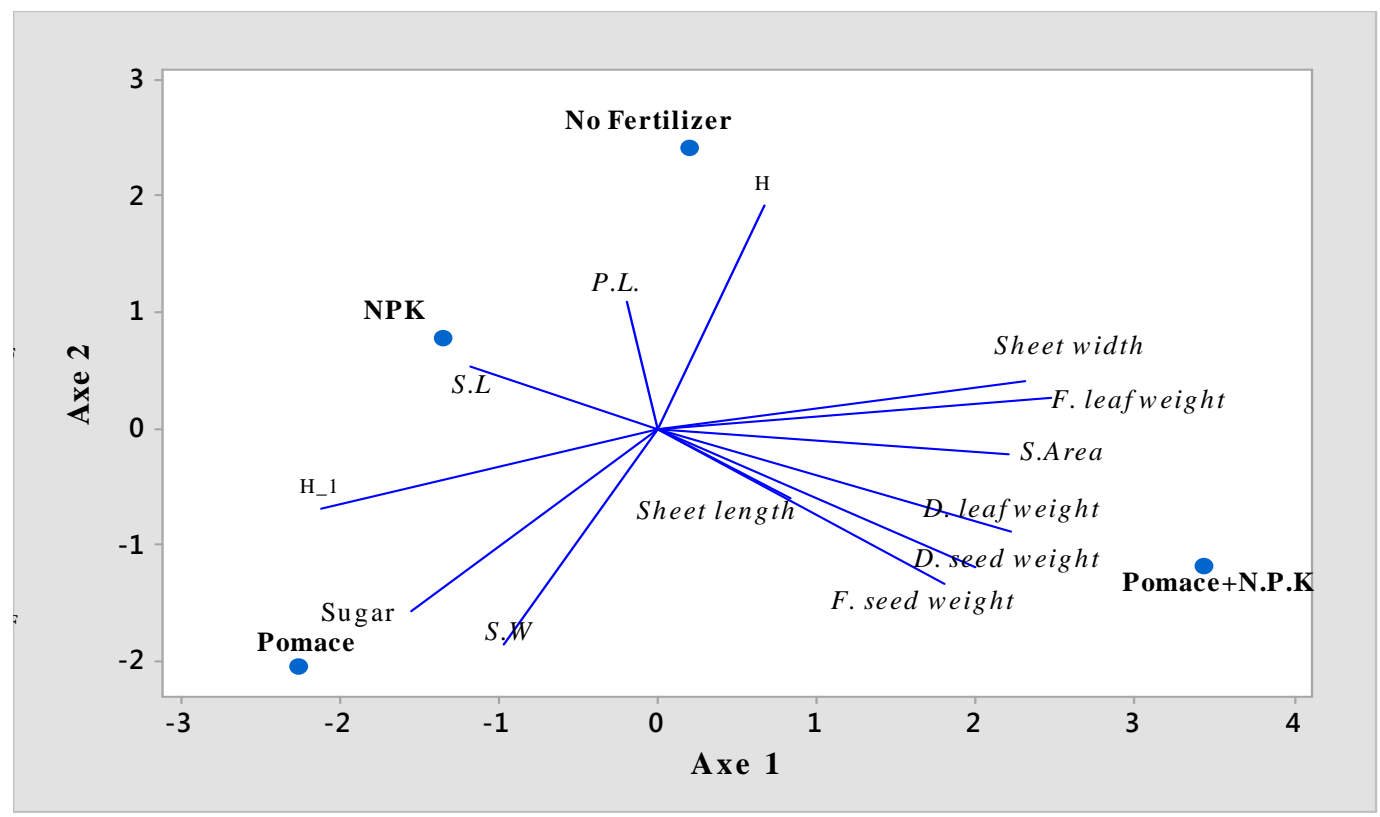

D. Seed weigth: Dry seed weight, F. Seed weigth: Fresh seed weight,

H1: Seed humidity, H: Leaf humidity, S.Area: Sheet area or leaf surface, F.

Leaf weigth: Fresh leaf weight, D. leaf weidth: Dry leaf weight, sheet length, sheet width,

P.L: Peduncle length. S.L: Fruit length, S.W: Fruit weigth.

Figure 4. Projection on the factorial plane of the A.C.P. factors of morphometric variations, types of fertilizers and\% of sugar. (Black Bigarreau) 
A.C.P. Symburst -Axis 1-2:

The multivariate analysis of fertilizer variables, morphometric measurements (morphological characters) and percentage of sugars implied a very significant correlation between N.P.K fertilizers and a large number of morphological characters, in particular the length of the leaf and the peduncle, the leaf surface and fresh leaf weight. The horizontal dispersion analysis gave us a projection of points on the factorial plane. These are the parameters whose contribution were much more significant and gave the positive meaning of axis 1 of the factorial plane and gave a scattering towards a tendency of N.P.K. (Figure 3). Axis 1 with an inertia percentage of $59 \%$ isolated all of the morphometric characters on the positive side. Axis 2 with a lower percentage of inertia (39\%) opposed the fertilization states including pomace, pomace + N.P.K and zero fertilizer. The factor diagram (Figure 3) also provided information on the distribution trend of the majority of the morphometric parameters related to the leaf and the peduncle with the presence of N.P.K fertilizer on the positive side of axis 1 and 2. On the negative side are positioned the characters related to the seed (dry and fresh weight) which both seemed to have a tendency with the presence of pomace. The moisture content variable was related to the dry and fresh weight of the seed and correlated negatively with the leaf variables. The percentage of sugar in the fruit had a distribution tendency towards a state of no fertilization.

A.C.P. Black Bigarreau Axis 1-2:

Unlike the Sunburst variety, the analysis of horizontal dispersion of fertilizer variables, morphometric measurements (morphological characters) and percentage of sugars implied a very significant correlation between NPK + pomace fertilizers and a large number of morphological characters, in particular width, leaf length, leaf area and the cool and dry weight of the seed. These parameters gave a positive meaning to axis 1 (Figure 4). With a percentage of inertia (39\%) and which opposed the states of fertilization, notably pomace, and the pomace + N.P.K fertilizer. A strong contribution was also recorded on the negative side of the axis with a very large trend of the parameter percentage of sugars and water content of the seed and the type of fertilizer by the pomace.

The values of the averages of morphometric measurements are positively correlated with those of the states of fertilization. In the case of the Sunburst variety, the correlations are very positive with the N.P.K. The greater absorption of nitrogen would have been favored by the crop's need for this element [19]. Nitrogen plays an essential role in the development of crops, especially in fruit growing [22-23]. It is the Black Bigarreau variety which has shown a great tendency to the N.P.K + pomace type of fertilization because the majority of morphometric characters are linked to the morphological development of the vegetative organs which correlated positively with this state of fertilization at the expense of others. Olive pomace contains various phenolic compounds such as polyphenols soluble in methanol-water and in acetone-water, polyphenols attached to cell walls, flavonoids and tannins (hydrolyzable and condensed) [24]. This study showed that this state of fertilization formed by an amalgam of pomace and N.P.K gives very good results for the Black Bigarreau. This method can export large amounts of mineral elements, especially nitrogen and potassium. For cations, absorption is faster for monovalent than for divalent [25-26].

The use of pomace mixed with N.P.K for the Black Bigarreau variety could have a positive effect on the physico-chemical properties of the soil by improving its water retention capacity [27]. In addition, olive pomace is very highly lignocellulosic and has a very slow degradation phase [28-29]. Lignin is one of the main components and the most resistant fraction in composting products [30-31]. As a result, we can establish a positive relationship between the improvement of soil properties by pomace, and the biomass which promotes the availability of nutrients and the growth of the Black Bigarreau variety [32]. It is also important to underline the strong correlation between the percentage of sugar contained in the fruit and fertilization with pomace which is displayed on the factorial level for the Black Bigarreau variety [33]. The $\mathrm{C} / \mathrm{N}$ ratio of the soil is often corrected by adding organic matter, in particular those contained in olive pomace. This promotes the long-term contribution to soil carbon [34].

\section{Conclusions}

The results of this study showed that olive pomace used as a fertilizer alone or in combination with N.P.K mineral fertilizers creates an advantage on the phenological and biochemical aspect, especially on the Black Bigarreau variety. The study showed that its use in combination with N.P.K fertilizers increases the carbon content of the soil, boosts the formation of May bouquets, and improves the water retention capacity of the clay-humic complex. Thus fruit yields can be improved for the Black Bigarreau variety, by opting for this approach. Pomace, as an amendment, could further reduce the acidity of the soil with an effect on improving the organoleptic quality of the fruit. Pomace composts 
could be an alternative green manure to chemical fertilizers in the future. He has yet to reveal all of these secrets . Other work is still essential, either in arboriculture or in other crops. It's used most often locally by farmers, who composted them to offer them a form of valorization of the by-product associated with an economic margin.

\section{Acknowledgements}

We would like to thank Mr. Chikhi for his kindness and his patience and for having also put at our disposal his firmness and his knowledge. May we address him our sincere thanks.

\section{References}

1. Ministry of Agriculture and Rural Development "MADR". (2012). The Agricultural and Rural Renewal on the Move: Review and Perspectives. May. www.minagri.dz.

2. Miranda, I., Simões, R., Medeiros, B., Nampoothiri, K.M., Sukumaran, R.K., Rajan, D., Pereira, H., Ferreira-Dias, S. (2019). Valorization of lignocellulosic residues from the olive oil industry by production of lignin, glucose and functional sugars. Bioresour. Technol, 292, 121936. [Cross Ref] https://doi:10.1016/j.biortech.2019.121936

3. Nunes, M.A., Pawlowski, S., Costa, A.S.G., Alves, R.C., Oliveira, M.B.P.P., Velizarov, S. (2019). Valorization of olive pomace by a green integrated approach applying sustainable extraction and membrane-assisted concentration. Sci. Total Environ, 652, 40-47. [Cross Ref] https://doi: 10.1016/j.scitotenv.2018.10.204

4. Moreno-Maroto, J.M., Uceda-Rodríguez, M., CoboCeacero, C.J., de Hoces, M.C., MartínLara, M.Á., Cotes-Palomino, T., López García, A.B., MartínezGarcía, C. (2019). Recycling of 'alperujo' (olive pomace) as a key component in the sintering of lightweight aggregates. J. Clean. Prod, 239, 118041. [CrossRef] https:// doi: 10.1016/i.jclepro.2019.118041

5. Roselló-Soto, E., Koubaa, M., Moubarik, A., Lopes, R.P., Saraiva, J.A., Boussetta, N., Grimi, N., Barba, F.J. (2015). Emerging opportunities for the effective valorization of wastes and by-products generated during olive oil production process, Nonconventional methods for the recovery of high-added value compounds. Trends Food Sci. Technol, 45, 296310. [Cross Ref] https://doi:10.1016/i.tifs.2015.07.003

6. Pérez-Jiménez, J., Díaz-Rubio, M.E., SauraCalixto, F. (2015). Obtainment and characterization of a potential functional ingredient from olive. Int. J. Food Sci. Nutr, 66, 749-754. [Cross Ref] [Pub Med] https://doi: 10.3109/09637486.2015.1095863

7. Berbel, J., Posadillo, A. (2018). Review and Analysis of Alternatives for the Valorisation of AgroIndustrial Olive Oil By-Products. Sustainability, 10, 237. [CrossRef] https://doi.org/10.3390/su10010237

8. Nefzaoui, A. (1987). Contribution to the profitability of olive growing by optimizing the value of by-products: olive tree economics seminar. Tunis, 20-22 Janvier. Science et Technique, Olivae (19). http://om.ciheam.org/om/pdf/s18/Cl010905.pdf
9. Ait Baddi, G.J., Cegarra, G., Merlina, J.C., Revel, \& Hafidi, M. (2009). Qualitative and quantitative evolution of polyphenolic compounds during composting of an olive-mill waste-wheat straw mixture. Journal of Hazardous Materials, 165, 1119-1123. https:// doi: 10.1016/.j.jhazmat.2008.10.102.

10. Alburquerque, J.A., J., Gonzálvez, D., García, \& Cegarra, J. (2007). Effects of a compost made from the solid by product ("Alperujo") of the two-phase centrifugation system for olive oil extraction and cotton gin waste on growth and nutrient content of ryegrass (Lolium perenne L.). Bioresource Technology, 98(4), 940-94. https:// doi: 10.1016/j. biortech.2006.04.014. 11. Alfano, C., G. Belli, D., Lustrato, D., Vitullo G., L. Piedimontem \& G. Ranalli. (2007). Modern strategies for oilmill residues exploitation: environmental and energetical opportunities. Proceedings of International Conference on New Technologies for the Treatment and Valorisation of Agro Byproducts, Terni, Italy.

12. Aubert, G. (1978). Soil analysis methods: national pedological documentation center. CR/DP Marseille, 198.

13. Zellam, W., \& Hamed, S. (2013). Assessment of two Cherry trees in the wilaya of Tlemcen. Mém. Ing. Agrono. Univ. Tlemcen,57, 59.

14. D.S.A. (2017). Mountainous areas of Tlemcen: Planting program of 15,000 Cherry trees. Time of Algeria 11, 12, 15.

15. Cucci, G., Lacolla, G., \& Caranfa, L. (2008). Improvement of soil properties by application of olive oil waste. Agronomy for Sustainable Development, 28, 521-526. https://doi.org/10.1051/agro:2008027

16. Muller, C., \& Larrope, E. (1993). Seed conservation and germination Rev. For. Fr, 3, 253-260.

17. Belbachir, N. (2016). Contribution to the study of the morphological characterization of wild cherry (Prunus avium L.) in the wilaya of Tlemcen. Master. Departement of Forestery.Univ.Tlemcen, 24, 25, 26.

18. Ruellan, A. (1970). The soils with a differentiated limestone profile of the low Moulouya plains (Maroc oriental): Contribution to knowledge of Mediterranean soils. Mém. O.R.S.T.O.M.N54. 302p.

19. Altieri, R., \& Esposito, A. (2010). Evaluation of the fertilizing effect of olive mill waste compost in short-term crops. International Biodeterioration and Biodegradation, 64,124_128. https://doi: 10.1016/j.ibiod.2009.12.002

20. Hodge, A. (2005). Plant uptake. In: Hillel D., ed. Encyclopedia of soils in the environment. Elsevier Academic Press, (3), 39-46.

21. Zaidi, F., Hassissene, N., Boubekeur, N., Bouaiche, A., Bouabdellah, M., Grongnet, J.F., \& Youyou, A. (2008). In vitro study of factors limiting the nutritional value of olive pomace: effects of fats and secondary metabolites. Livest Res Rural Dev, 20. https://doi.org/10.1007/s13594-013-0117-6

22. Fageria, N., \& Baligar, V. (2005). Nutrient availability. In: Hillel D., ed. Encyclopedia of soils in the environment. Elsevier Academic Press, 3, 63-71.

23. Petit, J., \& Jobin, P. (2005). Organic fertilization of crops. Longueuil, Quebec, Canada: Quebec Federation of Organic Agriculture.

https://cdnsciencepub.com/doi/pdf/10.4141/CJPS07160 
24. Nefzaoui, A. (1991). Valorization of olive tree byproducts. Mediterraneen Option, 16, 101-108.

25. Nyami, B. L., Sudi, C.K., \& Lejoly, J. (2016). Effect of biochar and leaves of Tithonia diversifolia combined with mineral fertilizer on the cultivation of maize (Zea mays L.) and the properties of a ferralitic soil in Kinshasa (R.D.C). Biotechnol. Agron. Soc. Environ, (1), 57-67.

https://doi.org/10.25518/1780-4507.12592

26. Gachengo, C., Palm, C., Jama, B., \& Othieno, C. (1999). Tithonia and Senna green manures and inorganic fertilizers as phosphorus sources for maize in Western. Kenya. Agrofor. Syst, 44, 21-36. https://doi.org/10.1023/A:1006339025728

27. Soltner, D. (2001). The basics of crop production. Volume III. The plant and its improvement 3rd edition: Ed.Sciences et techniques agricoles, 303.

28. Rasse, D.P., Rumpel, C., \& Dignac, M.F. (2005). Is soil carbon mostly root carbon? Mechanisms for a specific stabilization. Plant and Soil, 269(1), 341-356. https://doi.org/10.1007/s11104-004-0907-y

29. Tahir, M.M., Recous, S., Aita, C., Schmatz, R., Pilecco, G.A., \& Giacomini, S.J. (2016). In situ roots decompose faster than shoots left on the soil surface under subtropical no-till conditions: Biology and Fertility of Soils, 52(6), 853-865.
30. Diacono, M., \& Montemurro, F. (2010). Long-term effects of organic amendments on soil fertility: A review. Agronomy for Sustainable Development, 30, 401_422. https://doi.org/10.1051/agro/2009040

31. Bendi-Djelloul. M., Amrani S., Rovellini P\& Chenoune C. (2020). Phenolic compounds and fatty acids content of some West Algerian olive oils: Comunicata Scientiaea. Horticultural journal,11, 3247.. https://doi.org/10.14295/cs.v11i0.3247

32. Diacono, M. A., Ferri, D., Ciaccia, C., Tittarelli, F., Ceglie, F., Verrastro, V., Ventrella, D., Vitti, C., \& Montemurro, F. (2012). Bioassays and application of olive pomace compost on emmer: effectson yield and soil properties in organic farming. Acta Agriculturae Scandinavica Section B. Soil and Plant Science .pp-19. https://doi.org/10.1080/09064710.2012.663785

33. Roberto, A., \& Espositoa, A. (2009). Evaluation of the fertilizing effect of olive mill waste compost in shortterm crops. International Biodeterioration \& Biodegradation, $64 \quad$ (2), $124-128$. https://doi.org/10.1016/i.ibiod.2009.12.002

34. Montemurro, F., \& Maiorana, M. (2008). Organic fertilization as resource for a sustainable agriculture. In L. R. Elsworth, et al. (eds.), Fertilizers: Properties, applications and effects, 123-146. 